\title{
QUIMIOTERAPIA NEOADJUVANTE TORNA RESSECÁVEL CARCINOMA DE CABEÇA DE PÂNCREAS
}

\author{
NEOADJUVANT CHEMOTHERAPY MAKING A PANCREATIC HEAD CANCER \\ RESECTABLE
}

\section{Marco Antônio Cezário de Melo, ACBC-PE'; Christiane Violet $^{2}$}

\section{INTRODUÇÃO}

A ressecção cirúrgica era o único tratamento efetivo para os tumores de pâncreas até 1985, quando o "Gastrointestinal Tumor Study Group" (GITSG) observou melhora na sobrevida dos pacientes submetidos à quimioterapia (QT) + radioterapia (RT) após a ressecção cirúrgica1. Publicações mais recentes da "European Study Group for Pancreatic Câncer" e "Osaka University" (Japão), divulgado durante último encontro da "Society of Surgical Oncology" (New York, 2004) confirmaram o resultado promissor do tratamento adjuvante no câncer do pâncreas aumentando a sobrevida ${ }^{2}$.

Além disso, a QT neoadjuvante (pré-operatória), recentemente introduzida por grupos nas Universidades de Duke e Stanford ${ }^{1}$ tem permitido a ressecção de tumores irressecáveis ${ }^{3}$. A Gemcitabine $\left(\right.$ Gemzar) ${ }^{\circledR}$ mostrou melhores resultados que o 5-fluoruoacil na QT do câncer metastático do pâncreas ${ }^{4}$ pela inibição da angiogênese relacionada ao bloqueio dos receptores do fator de crescimento epidermal ${ }^{5}$. O nosso objetivo é descrever a redução e a posterior ressecção de uma tumoração pancreática após o uso de quimioterapia adjuvante pré-operatoria.

\section{RELATO DO CASO}

Paciente de 52 anos, feminino, com dor abdominal alta (cólica) e icterícia há 20 dias. Perda de $7 \mathrm{Kg}$. Os exames laboratoriais revelaram (hiperglicemia: $282 \mathrm{mg} / \mathrm{dl}$ ), elevação das transaminases $(\mathrm{TGO}=119 / \mathrm{TGP}=288)$, da fosfatase alcalina (730 UI). A bilirrubina total era de 12,5 $\mathrm{mg} / \mathrm{dl}$ (10,6 de direta). O CA 19.9 de $1.631 \mathrm{UI} / \mathrm{ml}$. A paciente era hipertensa controlada e foi colecistectomizada há 20 anos.

O ultra-som revelava dilatação da árvore biliar intra e extra-hepática e imagem hipoecóica na cabeça de pâncreas $(2,4 \times 2,9 \mathrm{~cm})$ comprimindo o colédoco distal. A tomografia mostrava dilatação das vias biliares intra-hepática, e do colédoco $(1,8 \mathrm{~cm})$ com redução progressiva do seu calibre na cabeça do pâncreas, que tinha o seu ducto dilatado, não havia metástases hepáticas nem hipertrofia linfonodal. A resso- nância confirmava massa na cabeça do pâncreas $(2,4 \times 3,0 \mathrm{~cm})$ e dilatação da via biliar inter e extra-hepática com afunilamento do colédoco intrapancreático.

A laparoscopia mostrou peritônio e parênquima hepático normais e a ultra-sonografia endocavitária, o ducto pancreático dilatado e o colédoco com $1,4 \mathrm{~cm}$ de diâmetro, penetrando na massa hipoecóica localizada na cabeça pancreática rechaçando a veia porta (Figura 1). À laparotomia identificamos a invasão da veia mesentérica superior, impedindo a sua ressecção. Foram retirados dois nódulos linfáticos retropancreáticos e realizada hepaticojejunostomia em alça exclusa. À histologia demonstrou hiperplasia linfóide reativa e histiocitose sinusal, sem sinais de malignidade.

Foram realizados cinco ciclos de QT usando Gemzar $1.000 \mathrm{mg} / \mathrm{m} 2$ por três semanas com um de descanso. Desde o primeiro ciclo houve diminuição do CA 19.9 para 44,0 UI/ml chegando a 18,7 UI/ml. Após a quimioterapia notou-se o desaparecimento da massa pancreática, que foi evidenciado pelos exames das imagens, e a melhora do estado geral com ganho ponderal $(9 \mathrm{Kg})$.

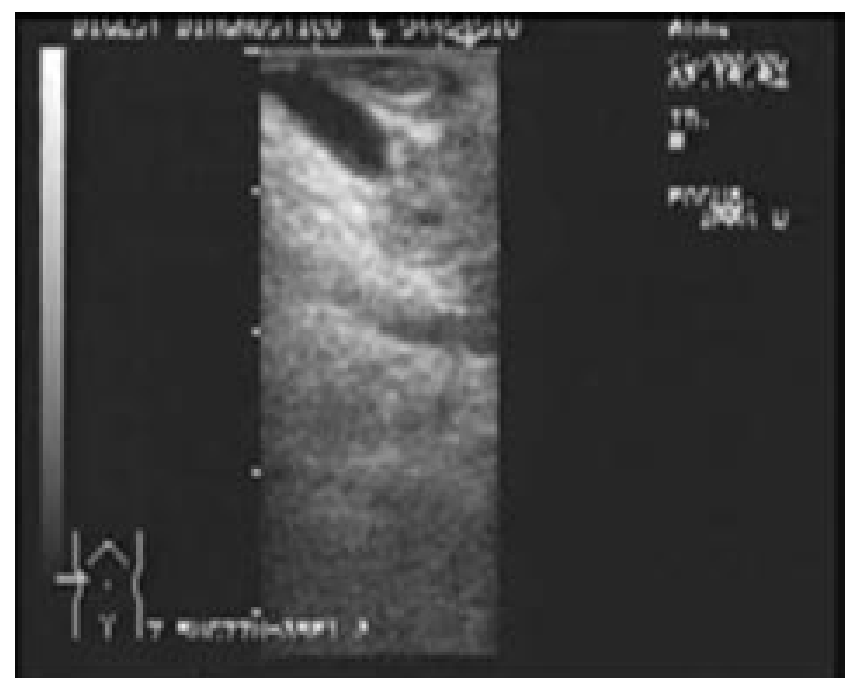

Figura 1 - Ultra-Som Endocavitário (Laparoscópico) mostrou colédoco dilatado penetrando na massa hipoecóica da cabeça pancreática rechaçando a veia porta.

1. Chefe da Equipe Cirúrgica da DIGEST - Recife - PE; Cirurgião do Serviço de Cirurgia Geral do Hospital das Clínicas - UFPE.

2. Oncologista Clínico da UNIONCO - Recife - PE; Oncologista Clínico do CEON - Hospital Universitário Oswaldo Cruz - UPE.

Recebido em 10/10/2005

Aceito para publicação 15/12/2005

Trabalho realizado na Clínica Cirúrgica DIGEST, Recife - PE. 
Após seis meses, nova laparotomia possibilitou ressecção de pequena tumoração pétrea $(1 \mathrm{~cm})$ localizada no processo uncinado. Foi realizada a gastroduodenopancreatectomia com reconstituição pancreatojejunal termino-terminal (telescopagem) e anastomoses hepaticojejunal e gastrojejunal (pré-cólica) termino-lateral, sem intercorrências sangüínea. Não foi necessário o uso de sangüinea.

O exame histológico revelou adenocarcinoma papilar invasivo, com extensas áreas hialinizadas, desmoplasia perineoplásica e invasão dos vasos e feixes nervosos intrapancreáticos. As margens estavam livres de neoplasia e não havia metástases no linfonodo peripancreático. A paciente evoluiu sem complicações, sendo re-encaminhada para o tratamento adjuvante.

\section{DISCUSSÃO}

A ressecção do tumor de cabeça pancreática é restrita $(10 \%)$ com mortalidade atual de $3 \%$ nos serviços especializados, alguns com mais de 100 casos consecutivos sem mortalidade ${ }^{1}$.

Estudo prospectivo e randomizado, comparando dois esquemas de RT+QT com grupo sem terapia mostrou elevação na sobrevida média de 13,5 para 19,5 meses, chegando-se à sobrevida de 1, 2 e 4 anos respectivamente de 68\%, 36\% e $24 \%$ com terapia adjuvante. Sugere-se uso concomitante do Alfa-Interferon com vantagens ${ }^{1}$.

O tratamento com Gemcitabine é superior ao uso do 5-fluorouracil com benefício de resposta clínica (23,8\% x 4,8\%) e sobrevida de 12 meses ( $18 \%$ x $2 \%$ ) quando usado para tumores irressecáveis ${ }^{4}$. Neste caso a gencitabina usada como neoadjuvante, tornou ressecável um tumor de cabeça de pâncreas.

Conclui-se que não podemos limitar o tratamento do adenocarcinoma de pâncreas à ressecção ou a procedimentos paliativos. $\mathrm{O}$ tratamento adjuvante pode aumentar a perspectiva de vida e em alguns casos, como neste, um tratamento neoadjuvante permitiu sua ressecção.

\begin{abstract}
We present a case of non-resectable head pancreatic cancer by mesenteric venous invasion in which treatment with Gemcitabine (Gemzar) $1.000 \mathrm{mg} / \mathrm{m} 2$ weekly for 3 weeks, followed by a 1-week rest, normalized CA 19.9 and promoted tumor resecability in a second operation (ultrasound, helicoidal tomography and magnetic ressonance exams). The value of the adjuvant treatment (radiochemotherapy) and the association with immunotherapy (Interferon) is discussed (Rev. Col. Bras. Cir. 2007; 34(4): 277-278).
\end{abstract}

Key words: Pancreatic neoplasms; Pancreaticoduodenectomy; Drug therapy; Neoadjuvant therapy, Gemcitabine.

\section{REFERÊNCIAS}

1. Postier RG. The challenge of pancreatic cancer. Am J Surg. 2003; 186(6):579-82.

2. Orellana C. Chemotherapy shows promise for pancreatic-cancer recurrence. Lancet Oncol. 2004; 5(5):255.

3. White RR, Hurwitz HI, Morse MA, Lee C, Anscher MS, Paulson EK, Gottfried MR, Baillie J, Branch MS, Jowell PS, McGrath KM, Clary BM, Pappas TN, Tyler DS. Neoadjuvant chemoradiation for localized adenocarcinoma of the pancreas. Ann Sug Oncol. 2001; 8(10):758-65.

4. Kozuch P, Petryk M, Bruckner HW. A comprehensive update on the use of chemotherapy for metastatic pancreatic adenocarcinoma. Hematol Oncol Clin North Am. 2002; 16(1):123-38.
5. Ellis LM. Epidermal growth factor receptor in tumor angiogenesis. Hematol Oncol Clin North Am. 2004; 18(5):1007-21.

Como citar este artigo:

Melo MC, Violet C. Quimioterapia neoadjuvante torna ressecável carcinoma de cabeça de pâncreas. Rev Col Bras Cir. 2007; 34(4). Disponível em URL: www.scielo.br/rcbc

Endereço para correspondência:

Marco Cezário de Melo

Rua Afonso Celso, 66 - Ap. 1501

Parnamirim

52060-110 - Recife - PE

E-mail: cezario@clinicadigest.com.br 